\title{
GENTRIFICAÇÃO E JUVENICÍDIO: UMA ANÁLISE DOS ÍNDICES DE MORTALIDADE JUVENIL NA CIDADE DE PORTO ALEGRE.
}

\author{
Giovane Antonio Scherer ${ }^{1}$ \\ Cristina Bettio Bragagnolo ${ }^{2}$ \\ Laura Barcellos de Valls ${ }^{3}$ \\ Maurício da Silva César ${ }^{4}$
}

\section{Introdução}

Gentrificação e Juvenicídio: Uma análise dos índices de mortalidade juvenil na cidade de Porto Alegre é produto do projeto de pesquisa em andamento $A$ Mortalidade Juvenil no Rio Grande do Sul: Uma Análise dos Índices de Violência Letal Juvenil e suas Possibilidades de Enfrentamento; estudo realizado pelo Grupo de Estudos em Juventudes e Políticas Públicas da Universidade Federal do Rio Grande do Sul, em parceria com a Frente de Enfrentamento a Mortalidade Juvenil em Porto Alegre. A investigação, com apoio da Fundação de Amparo a Pesquisa do Rio Grande do Sul (FAPERGS) e do Conselho Nacional de Desenvolvimento Científico e Tecnológico (CNPq), busca, dentre outros objetivos, mapear os dados vinculados à violência letal contra a juventude no Rio Grande do Sul, por meio da análise do Sistema de Informação sobre Mortalidade (SIM), no intuito de identificar as características dos jovens vítimas da violência letal e dos territórios de maior ocorrência de mortalidade juvenil na cidade de Porto Alegre.

Na primeira etapa da pesquisa, através da análise do Sistema de Informação de Mortalidade - SIM, evidencia que a mortalidade juvenil na cidade de Porto Alegre, expressão trágica e derradeira de uma trajetória de violações de direito, se apresenta hegemonicamente em bairros considerados atualmente de Zonas Periféricas: Restinga, Sarandi e Lomba do Pinheiro. Alcançando seu maior índice na Restinga, onde 17,68\% da violência letal contra a juventude foi praticada no período analisado.

\footnotetext{
${ }^{1}$ Universidade Federal do Rio Grande do Sul, Brasil. E-mail: giovaneantonioscherer@gmail.com ORCID: https://orcid.org/0000-0003-3847-7202

${ }^{2}$ Universidade Federal do Rio Grande do Sul, Brasil. E-mail: cristinabettiobragagnolo@yahoo.com.br ORCID: https://orcid.org/0000-0003-0212-8756

${ }^{3}$ Universidade Federal do Rio Grande do Sul, Brasil. E-mail: vllslaura@gmail.com ORCID: https://orcid.org/0000-0002-6655-1214

${ }^{4}$ Universidade Federal do Rio Grande do Sul, Brasil. E-mail: -mauriciocesarpoa@ gmail.com ORCID: https://orcid.org/0000-0002-6655-1214
} 


\section{Giovane Antonio Scherer, Cristina Bettio Bragagnolo, Laura Barcellos de Valls e} Maurício da Silva César

Considerando que tais índices estão dimensionados na periferia urbana da capital gaúcha e que a historicidade demonstra que estes territórios são fruto de processos incessantes de rediferenciação e reconfiguração espacial (Furtado, 2012), o conceito gentrificação desponta como elemento analítico privilegiado na apreensão da dinâmica da violência letal contra a juventude. Assim, importa desvendar as mediações político-ideológicas presentes tanto na historicidade do fenômeno, quando na atualidade desta dinâmica.

A formação sócio-histórica da capital gaúcha e suas atuais expressões territoriais - articuladas ao juvenicídio dimensionado na contemporaneidade demonstram que os elementos históricos que presentes na formação sócio-histórica do Brasil, presididos pela máquina colonial, se demonstram atualizados. Muito embora se encontrem atualizados em aparência, o núcleo duro do fenômeno se apresenta como simulacro de um passado que segue reatualizado no presente se expressando, inclusive, enquanto juvenicídio.

\section{A construção histórica da cidade de Porto Alegre: A unidade dialética da gentrificação e a favelização.}

As marcas da desigualdade social são perceptíveis de modo explícito na forma pela qual as cidades se desenvolvem espacialmente, uma vez que as dinâmicas das relações sociais de exploração, em um sistema determinado sob a égide do modo de produção capitalista, se reproduzem, dentre outras formas, no âmbito no espaço geográfico. É por meio da prática socioespacial que o mundo se revela em suas contradições, num movimento que aponta um processo em curso subsumido à reprodução das relações sociais no atual estágio do capitalismo (Carlos, 2020). A produção e reprodução do capital exigem que se realizem processos de circulação tanto de capital variável como de capital constante ${ }^{5}$ - sendo que a cidade expressa, na realidade concreta, à forma desta circulação e de seus efeitos deletérios para grandes massas de sujeitos que possuem, unicamente, a sua força de trabalho para sobreviver. Os bairros nobres com acessos e facilidades as mercadorias, se erguem entre muros, visíveis e invisíveis, onde a segregação de massas populacionais moradoras de espaços considerados "periféricos" se constitui como palavra de ordem, em cidades onde a

\footnotetext{
${ }^{5} \mathrm{Na}$ acepção marxiana, o termo capital variável se refere à força de trabalho, enquanto capital constante a matérias primas e os meios de produção.
} 
higienização social se constitui como um apelo, diante de processos que ocultam as raízes de um processo complexo de reprodução de relações sociais.

Se a desigualdade social é visível "a olho nu", seu complexo de complexos, que determinam a sua existência, é cada vez mais oculto por inúmeros processos alienantes e alienadores, de extrema funcionalidade para o mantimento do status quo diante do avanço de concepções neoliberais. Neste sentido, torna-se essencial compreender que o espaço é um produto social, construído por relações sociais, a partir da transformação da natureza pelo trabalho humano; sendo que as relações sociais de produção, consumo e reprodução social são determinantes na produção do espaço (Lefebvre, 1992). As cidades são divididas não apenas por muros, mas também por barreiras geográficas impostas pela dinâmica espacial do capital, que dá visibilidade para uma divisão de classes sociais dentro de determinados espaços, uma vez que esse modo de produção se materializa de múltiplas formas, inclusive por meio do desenvolvimento e gestão das cidades (Scherer, 2018). De um lado, grandes arranhacéus com proximidade a lojas, transporte públicos, escolas; de outro, moradias precárias, sem acesso a saneamento e com dificuldades de locomoção. Interessa conhecer, portanto, o território não tão somente no que tange suas particularidades de geografia física, considerando que a própria geografia nos habilita a investigar o território enquanto espaço vivido e dinâmico, portanto, espaço social.

As cidades brasileiras apresentam as marcas de um capitalismo periférico e dependente aos interesses internacionais, onde a superexploração da forma de trabalho deixa vestígios objetivos e subjetivos na vida da classe trabalhadora, que vivencia processos de precarização existencial. Os nítidos traços étnico-raciais deste processo são frutos de mais de 300 anos de processo escravista e uma "abolição" que carrega o pressuposto da violência e na negação de direitos. A cidade de Porto Alegre, muitas vezes oculta sob a imagem de uma cidade democrática e desenvolvida, revela as grandes contradições de um desenvolvimento que carrega consigo marcas de segregações históricas, que continuam vivas na forma pela qual a cidade vem se desenvolvendo e reproduzindo concepções que acarretam na ampliação da violação de direitos de seus moradores. Para Santos (1990), o território não é um conceito em si, uma vez que mostra todos os movimentos da sociedade, e que em si não é um conceito. Ele só se torna um conceito utilizável para a análise social quando considerado a partir de seu uso, a partir do momento em que é pensado justamente com aqueles que dele se utilizam. Assim, explica-se a expressão territorial da cidade de Porto Alegre no decorrer 


\section{Giovane Antonio Scherer, Cristina Bettio Bragagnolo, Laura Barcellos de Valls e Maurício da Silva César}

de sua historicidade, em que foi atribuído ao território diferentes títulos condizentes com o seu uso e dinâmica em determinados momentos históricos.

O território que abriga a hoje capital gaúcha nem sempre teve o nome de Porto Alegre, muito menos foi caracterizada como a capital de uma República desde sua origem. A origem do município de Porto Alegre remonta aos primórdios da efetiva ocupação portuguesa dos territórios do sul do país (Bittencourt, 2010). A capital do Estado do Rio Grande do Sul abriga o Governo Regional e Municipal. Porto Alegre é elevada à categoria de Vila em 1810 e, em 1822, a Vila de Porto Alegre recebe foros de cidade (Bittencourt, 2010). Situada à margem esquerda do lago Guaíba, junto à embocadura do Rio Jacuí, Porto Alegre, capital do estado do Rio Grande do Sul, pode ser considerada um dos maiores centros econômicos, culturais, políticos e econômicos do sul do país. Em 20 de setembro de 1835, durante a Guerra dos Farrapos ${ }^{6}$, a vila de Porto Alegre é tomada sob o jugo do conflito e é proclamado sob este território a capital da "República Rio-Grandense".

A antiga capital da República Rio Grandense, onde hoje está instituída a capital do Rio Grande do Sul, revela elementos na atualidade que estão mediados pela formação sócio histórica brasileira, particularizada ao sul do país. A antiga colônia portuguesa teve sua República erigida sob força de trabalho escravizada, sustentada também sob violência letal contra os povos originários do território brasileiro. $\mathrm{O}$ contexto transitório entre a antiga colônia e a jovem República nascida ao sul do globo expõe os parâmetros iniciais de um Brasil republicano. Esta nova república importava o advento capitalista para o sul da América e, este mesmo movimento articulava a importação da racionalidade positivista intencionada pela perspectiva dos antigos colonizadores, e que, portanto, se reatualizava através da perspectiva da nova elite territorializada na América.

Muito embora tenha se instituído um regime de ideário republicano, afere-se que este novo ideário reproduz velhas contradições, ao passo que é também gerador de novas velhas contradições que se encontram sintonizadas à reprodução da historicidade; demonstrando-se assim, mecanismo de reatualização destas contradições. O ideário positivista, no bojo do republicanismo no Brasil articula-se ao constructo de um patrimônio nacional que, apesar de emergir em uma Velha República Latino

\footnotetext{
${ }^{6}$ Guerra ocorrida no Rio Grande do Sul de 1835 a 1845 tendo como propulsores a insatisfação com a situação econômica do estado e o conflito dos interesses da elite rio-grandense com o Governo Imperial. O fim da guerra se deu com a assinatura do acordo de Ponche Verde no qual várias concessões foram feitas pelo Governo às elites (Kuhn, 2002).
} 
Americana, sinalizava de forma contraditória que suas raízes deveriam ser europeias, contradizendo a própria história fundante do Brasil, que buscava ser apagada, ou melhor: branqueada.

No período oitocentista houveram ondas migratórias europeias incentivadas pelo Estado brasileiro, intencionando um estado-brasileiro-europeu. Através destas, foi incorporada ao território brasileiro força de trabalho livre, branca e hegemonicamente europeia ao contingente de trabalhadores locais. Especificamente no território gaúcho, incorporou-se a força de trabalho de imigrantes italianos e alemães, visando a substituição dos já territorializados trabalhadores negros. Trabalhadores estes perpassados preteritamente pela escravização por parte da elite branca: sendo eles próprios ou seus antepassados tendo sido arrancados à força do seu continente pela máquina colonizadora europeia e destinados ao trabalho compulsório no sul do Brasil (Bittencourt, 2010).

A escolha política pela importação de mão de obra oriunda da Europa, em detrimento da incorporação no mercado de trabalho por africanos e seus descendentes já territorializados no país no período é analisada sob o paradigma do racismo científico, considerando que este não foi superado à transição republicana. A escolha pela substituição da força de trabalho por razões raciais expressa o projeto político de branqueamento da sociedade brasileira, e essa é uma política de construção de imagem e identidade nacional idealizada pela elite: esse projeto associa a imagem dos brancos $-\mathrm{e}$ especificamente os europeus ocidentais - a uma suposta raça superior e civilizada, diferente dos africanos, negros e indígenas; e, portanto, superior também aos latinoamericanos. Estes últimos estariam associados a características inferiores e primitivas, selvagens, necessitando ser civilizados. Ratifica-se assim, o paradigma do racismo científico, associado à ideia de supremacia racial branca e instituído ao sul da América.

A cidade de Porto Alegre, mesmo quando analisada sob a luz da contemporaneidade, apresenta a reprodução de valores erigidos na colônia portuguesa. Tendo ultrapassado o status oficial de colônia; também superados os primórdios do ideário republicano no Brasil, revela-se a operacionalização do capital através de processos incessantes de rediferenciação e reconfiguração do território urbano. Processos esses comuns às cidades localizadas em territórios onde o modo de produção hegemônico é o capitalista. Expondo, dessa maneira, a não superação do paradigma e mito de supremacia racial na realidade brasileira, mesmo quando sob ideário republicano. Segundo Rolnik: 
Se, no mundo escravocrata, o devir negro era sinônimo de subumanidade e barbárie, na República do trabalho livre, negro virou marca de marginalidade. $\mathrm{O}$ estigma foi formulado a partir de um discurso etnocêntrico e de uma prática repressiva; do olhar vigilante do senhor da senzala ao pânico do sanitarista em visita ao cortiço; do registro esquadrinhador do planejador urbano à violência das viaturas policiais nas vilas e favelas. (Rolnik, 1989, p. 16) (grifo dos autores).

O crescimento urbano de Porto Alegre se constitui como um produto de um processo histórico marcado pela desigualdade social no espaço da cidade, buscando construir espaços geográficos de segregação. Conforme ressaltam Polidoro e Demichei (2015), os projetos de modernização, executados ao longo do século XX e XXI na cidade de Porto Alegre, vislumbram um espaço heterogêneo, marcado pela divisão espacial da população, sobretudo a partir da renda e cor, e o acesso ao mercado formal de trabalho, com uma também desigual distribuição dos elementos essenciais para a vida na cidade.

No desenvolvimento industrial de Porto Alegre, em função da densidade demográfica e dos impactos sociais do crescimento populacional, constituiu-se como um projeto de "crescimento" e "desenvolvimento" a remoção da população mais pobres das áreas centrais. O Estado iniciava a implantação de infraestrutura, em especial nos bairros adjacentes ao Centro Histórico, que passaram a sediar a residência da classe média, como os comerciantes e imigrantes (Polidoro; Demichei, 2015). Desta forma, a remoção das populações mais empobrecidas das áreas mais centrais em Porto Alegre para bairros mais afastados era essencial para a consolidação do novo projeto de cidade, sendo um processo que respondia a ordem tecnocrática vigente, de base racional, modernizante e higienizante: materializada na seleção daqueles que poderiam usufruir dos benefícios da urbanização, em detrimento dos que seriam enviados para longe da cidade "moderna" (Polidoro; Demichei, 2015).

O processo de urbanização de Porto Alegre, crescimento da cidade de forma mais intensa, se deu a partir da década de 1940 acompanhando o contexto do processo de desenvolvimentismo brasileiro. No entanto, os investimentos na reorganização e melhorias urbanas mantiveram-se restritos à área central, enquanto os bairros mais afastados do centro, ao passo que outros bairros, mantiveram-se com precários acessos com relação à água encanada, iluminação pública e energia elétrica. Conforme Farinon (2015), somente a partir da década de 1940 que Porto Alegre começou a contabilizar o surgimento de loteamentos irregulares, que eram construídos sobre áreas impróprias e sem infraestrutura e sem nenhuma intervenção do poder público, e à medida que os 
loteamentos iam sendo estruturados, recebiam instalação de redes de esgoto, abastecimento de água, pavimentação e iluminação entre outros serviços, os preços dos terrenos e os custos de vida iam crescendo e a população mais pobre que ali residia era obrigada a procurar outras áreas precárias e mais distantes dos centros urbanos e de seus locais de trabalho.

Desta forma, localiza-se a partir da década de 40 a operacionalização de políticas de desenvolvimento urbano que coadunam com tal paradigma na cidade de Porto Alegre, como por exemplo, o projeto Remover para Promover (Gamalho, 2010). O referido projeto originou a expressão territorial que hoje é conhecida como Restinga ${ }^{7}$. Este incidiu sob as décadas de 60 e 70, quando foi apresentado sob discurso modernizante. Muito embora a forma como esse foi apresentado ao público - enquanto uma promessa de progresso e desenvolvimento - a dinâmica do processo revela seu caráter higienista, vinculado ao desejo político pelo branqueamento do perímetro urbano - em especial, da Zona Central - de Porto Alegre. Vinculando-se assim, também, à tendência histórica do paradigma e mito da supremacia racial, amparada pelo racismo científico, constructo cultural que preside tendências no imaginário nacional e particularmente do Rio Grande do Sul. Através da política de Estado Remover para Promover, foi mobilizada a população negra e trabalhadora residente à zona central em direção ao território hoje conhecido como Restinga. Foi publicizado pelo jornal Zero Hora $^{8}$ à época:

Vocês conhecem a Restinga? Quarenta minutos de jipe, quarenta centavos novos de ônibus... A Restinga não é uma vila, nem uma granja, nem um loteamento. Não é coisa alguma. Um deserto. Areia fina e sêca, côr de cinza. Nem capim, nem árvores... capões de arbustos secos, também cinzentos, barbas de pau, plantas em agonia, uma sanga esverdeada de limo... Nem luz, nem água, nem comércio, nem hortas, nem indústria... nem trabalho. (...) A Restinga não tem coisa alguma. Isto é, tem gente. E malocas. Favela da Ilhota, que na solidão da Restinga tornou-se cinco vêzes favela. Acabada a vantagem do comércio camarada da zona, que fiava por semana, e até por quinzena... Acabada a vantagem da patroa compreensiva, que dava roupa velha e restos de comida para a faxineira... Acabada a vantagem dos lavados de roupa... Acabada a vantagem das reformas de vestidos... Acabada a novela ouvida no rádio do vizinho... Acabada a consulta à Santa Casa... Acabada a Feira Livre... Acabada a escola... Acabados os médicos, a farmácia, a Polícia, os bombeiros, os vizinhos...

\footnotetext{
${ }^{7}$ Bairro pertencente à cidade de Porto Alegre (RS), fora reassentado pela prefeitura de Porto Alegre na década de 60, está localizado atualmente na zona sul da cidade há $22 \mathrm{~km}$ do centro da cidade. É considerado um bairro bastante populoso e marcado pela vulnerabilidade social (FASC/POA, 2013).

${ }^{8}$ É considerado um dos jornais de maior circulação do Brasil, editado em Porto Alegre e organizado pelo grupo RBS.
} 
[sic] (Faillace, Zero Hora, 18 maio. 1967, p. 12-3)". (Gamalho, 2010:26) (grifo dos autores).

A favela da Ilhota, que na solidão da Restinga tornou-se cinco vezes favela expressa a materialização do Projeto Remover para Promover em sintonia com os desejos pelo uso do território, articulados à dinâmica da sociedade brasileira em um período em que o advento capitalista já se encontrava em sua fase madura. Situa-se não somente o processo de rediferenciação e reconfiguração territorial operacionalizado pelo Estado que originou a Restinga, e sim, os processos incessantes de rediferenciação e reconfiguração do espaço que produziram o que se conhece hoje como cidade de Porto Alegre. Dessa forma, se insere em análise o conceito gentrificação articulado a dimensão sócio histórica do espaço, intencionando desvelar as mediações que produziram sua atual expressão territorial.

O termo gentrificação emerge na década de 60 através dos estudos da socióloga inglesa Ruth Glass. Nestes, são descritos processos iniciados na década de 50 na cidade de Londres em que, bairros localizados à região central da capital inglesa ocupados à época pela classe trabalhadora. Tais bairros encontravam-se em situação de deterioração Alcântara, 2018). Supostamente, em razão de tais condições de deterioração ou habitabilidade, estes passam a ser revitalizados e transformados em territórios de moradia para a classe média: gentry ${ }^{9}$.

No entanto, foi na década de 1970 que o termo veio a popularizar-se enquanto conceito na Europa e em países da América do Norte, tais como Estados Unidos e Canadá. Em 1980 o Oxford Dictionary definiu gentrificação como um movimento de famílias de classe média para áreas urbanas, causando a valorização das propriedades ali existentes e causando efeitos secundários, como a expulsão das famílias pobres ali assentadas. Em 1982, de forma similar, o American Dictionary definiu gentrificação como recuperação de propriedades urbanas deterioradas, especialmente em bairros ocupados pela classe trabalhadora, pela classe alta e média.

$\mathrm{O}$ conceito de gentrificação tem sido relacionado com frequência a um fenômeno que acontece no mercado residencial. No entanto, conforme sinaliza Furtado (2014), se olharmos para trás, para as descrições de alguns processos de remoção de trabalhadores, percebemos que o processo de gentrificação parece não um novo, mas, antes, a nova forma de um velho processo:

\footnotetext{
${ }^{9}$ Termo utilizado na Inglaterra para designar a classe média. O termo tem origem na designação da classe palaciana situada imediatamente abaixo da nobreza no ranking social em inglês.
} 
A melhoria das cidades, acompanhando o crescimento da riqueza, através da demolição de quarteirões mal construídos, a construção de palácios para bancos, grandes depósitos, etc., o alargamento de ruas para o tráfego comercial, para luxuosas carruagens e para a introdução dos bondes, etc., erradicam os pobres para lugares escondidos ainda piores e mais densamente ocupados. (Marx, 1967, v. 1, p. 657)". (Furtado, 2014: 342).

O conceito aplicado em dimensão sócio histórica, não tão somente em dimensão fenomenológica vai ao encontro com o que Harvey (2005: 53) caracteriza enquanto produção capitalista do espaço, uma vez que este espaço se assemelha à paisagem do capital e passa a ser representado na forma de uma paisagem física, criada à sua própria imagem. Para Gamalho (2010), na cidade de Porto Alegre a partir da década de 40,

\begin{abstract}
As vilas de malocas não harmonizavam com o ideal de modernidade e progresso $e$ ocupavam setores estratégicos para o desenvolvimento urbano, mas consistiam no modo pelo qual um segmento social produzia a própria existência e seu lugar. Paralelamente ao crescimento das vilas, a cidade passava por um processo de intensas transformações, e a esse crescimento populacional era atribuído o caráter de desorganizado, necessitando, portanto, de ordenamento. A pobreza tornava-se visível no modo de habitar, de ocupar a cidade, e a maloca era a materialização do processo. (Gamalho, 2010: 65) (grifo dos autores)
\end{abstract}

Conforme sinalizado pela autora, a década de 40 é marcada pelo aceleramento da industrialização nacional sob a égide do capital monopolista, bem como pelo aceleramento de mudanças das paisagens urbanas através de processos de rediferenciação do território. A aceleração do tempo e do espaço que não cessam em tal década, e, conforme Harvey (2005), cria a paisagem do capital à sua própria imagem, em incessantes processos de reconfiguração do espaço urbano. Esta acumulação particularizada por processos de reconfiguração e rediferenciação territorial incessantes pode ser operacionalizada pelo mercado imobiliário, pelo mercado da construção civil, além de outros mercados correlatos sob aval e incidência estatal.

$\mathrm{Na}$ realidade brasileira e porto alegrense, este processo verificado como gentrificação promove a higienização social nas áreas urbanas - especialmente centrais - e o branqueamento de territórios marcadamente privilegiados não tão somente pelo aparelhamento de serviços públicos, como também pela presença de oferta de bens e serviços e, consequentemente, pelo mercado de trabalho oriundo desta esfera. Dessa maneira, se removem sujeitos sociais socialmente marcados por raça e classe da zona urbana central através da iniciativa estatal; estando, assim, tais iniciativas vinculadas aos interesses expressos pelo capital e operacionalizados pela elite econômica; intencionando, dessa forma, o uso do espaço sob égide do modo capitalista de produção. 


\section{Giovane Antonio Scherer, Cristina Bettio Bragagnolo, Laura Barcellos de Valls e}

Maurício da Silva César

Através de processos incessantes de rediferenciação e reconfiguração do espaço urbano produz-se, finalmente, o território nas sociedades capitalistas. Nesta expressão de produção territorial, revelam-se também as lutas de classes.

Tendo em vista que a gentrificação enquanto produção capitalista do espaço na capital do Rio Grande do Sul não se inicia neste século e nem neste período da acumulação capitalista, se faz necessário um movimento analítico a fim de desvendar as múltiplas mediações desse fenômeno historicamente processado, no intuito de desvelar as raízes fundantes do fenômeno para além de sua aparência. Apreender apenas a aparência do fenômeno incidiria na naturalização do constructo da história oficial e, portanto, em sua reprodução. Assim, a captura das mediações político-ideológicos que sancionaram o desenvolvimento e continuidade do processo de rediferenciação e reconfiguração territorial incessantes na capital gaúcha desponta como elemento analítico para a compreensão da dimensão do território em perspectiva de totalidade. Localizando ainda, neste campo analítico, a posição da economia política constituída pelo modo de produção capitalista no Brasil, que o situa enquanto país de desenvolvimento capitalista dependente, ou seja: localizado na periferia do sistema.

O processo de gentrificação atravessa os tempos na história de Porto Alegre, se reconfigurando, por meio de diversas feições, em estratégias da gestão que cidade que, muitas vezes, se calca em concepções que visam a "limpeza social" de espaços públicos. Desta forma, os segmentos mais pobres são expulsos de determinados territórios, jogados a margem para as periferias, seja por desapropriação de suas terras, altos de custo de vida, entre outras questões, não lhes permitindo ter seus direitos, acesso a serviços básicos como escolas e hospitais e distantes de seus locais de trabalho, pois grande parte das ofertas de empregos se concentram nos espaços centrais das cidades.

O processo de gentrificação acarreta de um lado a produção de "bairros nobres" e de outro a ampliação de espaços de favelização em determinados territórios, em uma nítida contradição estrutural da cidade sob os signos neoliberais. A ampliação de espaços de favelização acarreta na privação de massas populacionais do direito à cidade, acarretando em uma série de violações de um conglomerado populacional cada vez mais amplo. Conforme Davis (2006), por toda parte os pobres urbanos são forçados a habitar terrenos perigosos, vulneráveis às diversas expressões de violência diante da tendência macroeconômica real do trabalho informal que acarreta na pobreza absoluta. A história de Porto Alegre, ontem e hoje, apresenta simultaneamente processos de gentrificação e 
favelização como uma unidade dialética contraditória que acarreta em uma intensa violência estrutural para grande parte da população. É, exatamente, nesses espaços gentrificados que se concentram os maiores índices de violência letal, como a face mais perversa e trágica da violência estrutural.

\section{As marcas do juvenicídio nos Territórios da Cidade de Porto Alegre.}

A unidade dialética composta pela gentrificação e favelização, são em verdade, expressões de um único processo conformado pela produção e reprodução do capital, em tempos de ampliação de sua crise estrutural. Grandes segmentos populacionais, moradores dos territórios considerados periféricos, são afetados pelos efeitos deletérios desses processos, tanto por meio de suas condições materiais, como por suas expressões simbólicas. A falta ou o acesso precário a serviços básicos para a reprodução da vida social marcam presença nesses espaços, sendo que, além da precarização estrutural com relação ao acesso as políticas públicas, que impacta nas condições objetivas, os segmentos populacionais residentes nesses espaços vivenciam intensos processos de violência física e simbólica ${ }^{10}$, sendo constantemente associados a "sujeitos violentos" e "desviantes" por habitarem em tais espaços. Tais construções sociais frequentemente são associadas às juventudes residentes desses espaços, uma vez que, conforme afirma Sales (2007), quase tudo que os jovens pobres questionam e produzem, assim como praticamente todas as formas de reação são interpretadas socialmente como violência, já que este é um dos recursos acionados pelos múltiplos poderes da ordem burguesa que associa a juventude pobre a transgressores, pertencentes a classes perigosas.

Nesse sentido, tal construção social reatualiza concepções historicamente presentes na construção social da sociedade brasileira, e constitui como uma das características do neoconservadorismo que se legitima pela criminalização da pobreza e da militarização da vida cotidiana, implicando na violência contra o outro (Barroco, 2011: 209). A ideia de um "inimigo comum" da sociedade, que precisa ser combate é disseminada amplamente, na maioria das vezes, pela mídia hegemônica, criando um "discurso

\footnotetext{
${ }^{10}$ Importante considerar que tais dimensões se relacionam a constante violência estrutural vivida nesta forma de sociabilidade, uma vez que a violência estrutural constitui o "pano de fundo" das demais formas de violência e tem como principal característica sua discrição, envolvendo valores e normas necessárias ao desenvolvimento capitalista, sustentando assim a naturalização das desigualdades sociais e da pobreza. Deste modo, é possível afirmar que a maioria da população é atingida pela violência estrutural, uma vez que esta se encontra vinculada às relações da produção e reprodução do capital. Entende-se, assim, que o fenômeno da violência, mesmo não sendo exclusivo do modo de produção capitalista, acentua-se com a dinâmica da atual ordem societária (Silva, 2009).
} 
comum", no âmbito da superficialidade analítica dos fenômenos. É por meio deste processo que ocorre uma inversão na análise do real, onde tais populações, moradoras destes territórios, passam a ser criminalizadas devido à situação de violência estrutural que vivenciam (Scherer, 2018). Evidencia-se nesse contexto a transversalidade do racismo estrutural como componente essencial no processo de criminalização da pobreza.

A expressão mais trágica deste processo é marcada pela dinâmica da mortalidade presente nesses territórios, uma vez que é nesses espaços que se vivencia com maior intensidade a violência urbana, tanto canalizada pelas relações do tráfico de drogas varejista, como pela repressão de forma violenta dos aparelhos estatais. O Brasil constitui-se como um país com altos índices de homicídios do mundo, sendo que essa dinâmica homicida tem ceifado vidas especialmente das juventudes ${ }^{11}$ brasileiras. O estado do Rio Grande do Sul não foge destas estatísticas, sendo que a concentração de municípios com as maiores taxas de homicídios localiza-se na região metropolitana da capital (IPEA, 2019). A capital gaúcha ocupa a terceira posição no que tange às cidades mais violentas do estado do Rio Grande do Sul e $66^{\mathrm{a}}$ no ranking das cidades mais violentas do país, com 58,1 casos de morte violenta para cada 100 mil habitantes (IPEA, 2019).

Na perspectiva de compreender como vem se constituindo a relação entre os altos índices de mortalidade juvenil e o acesso das juventudes às políticas públicas no Rio Grande do Sul, vem sendo desenvolvido um estudo realizado pelo Grupo de Estudos em Juventudes e Políticas Públicas da UFRGS, em parceria com a Frente de Enfrentamento a Mortalidade Juventude em Porto Alegre - FEMJUV ${ }^{12}$. A investigação, com apoio da Fundação de Amparo a Pesquisa do Rio Grande do Sul - FAPERGS e do Conselho Nacional de Desenvolvimento Científico e Tecnológico - CNPq, busca, dentre outros objetivos, mapear os dados de mortalidade juvenil por homicídio no Rio Grande do Sul, por meio da análise do Sistema de Informação sobre Mortalidade, a fim de identificar as

\footnotetext{
${ }^{11}$ Considera-se juventude, conforme a Lei 12.852, de 5 de agosto de 2013, que institui o Estatuto da Juventude, em que são consideradas jovens as pessoas com idade entre 15 (quinze) e 29 (vinte e nove) anos de idade. A pluralização do termo indica, conforme Scherer (2017), a necessidade de entender esta categoria por elementos que transcendem as marcações etárias, compreendendo as juventudes como uma construção social, na qual se conjugam, entre outros fatores, estereótipos, momentos históricos, múltiplas referências, além de diversificadas situações de classe, gênero, etnia, grupo, etc.

${ }^{12}$ Configura-se como uma rede de profissionais vinculados às políticas públicas como assistência social, saúde, sócio jurídico, previdência social, educação; bem como, movimentos sociais, militantes na área dos direitos das juventudes, grupos de pesquisas, dentre outros. Nesse sentido, constitui-se enquanto um espaço de articulação entre a sociedade civil e o poder público para pensar de maneira coletiva, propostas que possam realizar o enfrentamento à mortalidade juvenil no município, desde agosto de 2016.
} 
características dos jovens vítimas da violência letal e dos territórios de maior ocorrência de mortalidade juvenil na cidade de Porto Alegre. Para o alcance do referido objetivo foi realizada a análise documental e o tratamento estatístico do banco de dados do Sistema de Informação de Mortalidade - SIM, desenvolvido pelo Ministério da Saúde em 1975, e enquanto produto da unificação de mais de quarenta modelos de instrumentos utilizados, ao longo dos anos, para coletar dados sobre mortalidade no país. O SIM possui variáveis que permitem, a partir da causa mortis atestada pelo médico, construir indicadores e processar análises epidemiológicas que contribuam para a eficiência da gestão em saúde (Brasil, 2017). No âmbito desse sistema, busca-se a análise dos dados específicos de mortalidade juvenil, dos jovens de $12^{13}$ até 29 anos, vitimizados na cidade de Porto Alegre nos anos de 2015 a 2019.

A análise preliminar do estudo indica que as taxas de homicídio de adolescentes e jovens, no respectivo período, apresentaram-se superiores aos homicídios das demais faixas etárias, representando $1.712(54,12 \%)$ mortes por violência letal de adolescentes e jovens, enquanto foram registradas $1.451(45,87 \%)$ mortes das variadas faixas etárias. Sendo o ano de 2016 o registrado como o mais violento na cidade, registrado como o ano em que mais ocorreram homicídios de jovens, representando $58 \%$ do total de homicídios (Barros; et. al., 2017).

Em consonância às taxas populacionais nacionais, a capital gaúcha tem maior predominância da população adulta $(43,19 \%)$, seguida pela população idosa $(21,83 \%)$ e pela população jovem $(16,44 \%)^{14}$ (IBGE, 2019). O Brasil vem, há alguns anos, enfrentando uma alteração da sua pirâmide etária, passando de um país jovem para um país adulto e com previsão para ser um país de idosos nas próximas décadas. Esse quadro, no entanto, torna as altas taxas de mortes na juventude bastante preocupantes podendo gerar fortes impactos sociais e econômicos nos próximos anos, além de acabar com inúmeros sonhos e vidas jovens.

Quanto às idades das vítimas de homicídio na cidade de Porto Alegre, no ano de 2015 houve mais mortes na faixa etária dos 18 aos 19 anos, enquanto no ano de 2016 e no ano de 2018 a faixa etária que mais fora vítima da violência letal foram os jovens de

\footnotetext{
${ }^{13}$ Optou em analisar, para além dos dados de mortalidade de jovens, também de adolescentes uma vez que se observa na literatura um avanço para a dinâmica homicida em adolescentes cada vez mais jovens na realidade brasileira.

${ }^{14}$ Os recortes de idade utilizados para o respectivo cálculo são definidos pelo Estatuto da Criança e do Adolescente e do Estatuto da Juventude, no entanto, os grupos de idade do IBGE não estão em consonância à Legislação Nacional, portanto pode haver alteração nos números de crianças e adolescentes, sendo descrita acima uma porcentagem aproximada.
} 


\section{Giovane Antonio Scherer, Cristina Bettio Bragagnolo, Laura Barcellos de Valls e} Maurício da Silva César

18 anos, em 2017 a faixa etária que apresentou maior taxa de mortalidade fora a dos 21 anos e no ano de 2019 as taxas apresentaram-se maiores entre os jovens de 19 anos. Considerando os dados expostos pode-se afirmar que os homicídios tem se apresentado como a principal causa das mortes de jovens em âmbito nacional (IPEA, 2020) e em Porto Alegre não tem sido diferente, enfrentando um fenômeno conhecido como juvenicídio.

O termo juvenicídio é cunhado pelo pesquisador mexicano José Manuel Valenzuela para designar o fenômeno da mortalidade juvenil por meio dos homicídios. Tal termo ilustra a condição de mortalidade juvenil, provocada pela dinâmica societária contemporânea que desestabiliza vidas de jovens em todo globo, especialmente em países de desenvolvimento capitalista tardio e periférico (Scherer, 2018). Para Velenzuela (2015) o juvenicidio se constitui de diversos fatores que incluem a precarização, pobreza, desigualdade, estigmatização, tendo como eixo central a estratificação social baseada em relações de subalternização. Nesse sentido, o juvenicidio inicia com a precarização da vida dos jovens, a ampliação da sua vulnerabilidade e a diminuição das opções disponíveis para que possam desenvolver seus projetos de vida (Valenzuela, 2015).

A precarização da vida, ou, nos termos de Alves (2009), a precarização existencial é aspecto central na dinâmica dos homicídios no Brasil, sendo que a moralidade juvenil se constitui como a expressão mais trágica de uma trajetória de violações de direito. Sendo assim, observa-se que as localidades mais impactadas pela dinâmica do processo de gentrificação/favelização são aquelas que apresentam taxas mais expressivas com relação à mortalidade juvenil em Porto Alegre. Quanto aos bairros mais violentos para adolescentes e jovens no município de Porto Alegre, com base no período nos homicídios ocorridos de 2015 a 2019, destacam-se a Restinga (17,68\%), Lomba do Pinheiro $(11,17 \%)$ e Sarandi $(10,41 \%)$. Com base nos territórios onde mais ocorreram homicídios de adolescentes e jovens na capital pode-se relacionar o fenômeno do juvenicídio, dentre outros fatores, ao tráfico de drogas, a pobreza, a defasagem nas políticas públicas e a desigualdade social ${ }^{15}$, visto que, se tratam de bairros periféricos e com grande vulnerabilidade social, “a conjunção de drogas, política

\footnotetext{
${ }^{15} \mathrm{O}$ Índice de Gini que mede a desigualdade social indo de 0 (perfeita igualdade) à 1 (total desigualdade) da cidade de Porto Alegre no ano de 2010 fora de 0,489, enquanto o índice do Brasil no respectivo ano era de 0,525 (IBGE, 2010).
} 
e poder, deixou um saldo gigantesco de violência, morte e deterioração social" (Valenzuela, 2015: 33).

Deste modo, a dinâmica espacial, na forma pela qual se estruturam as relações sociais nas cidades incide de diversas maneiras na vida da população moradora de determinados territórios, e de tal forma, que podem ser determinantes na vida ou na morte destes sujeitos. A Restinga, enquanto fruto do processo de gentrificação e favelização de Porto Alegre, concentra as maiores taxas de juvenicídio de 2015 a 2019 (163 mortes no período), sendo considerado um dos bairros mais populosos do município com uma população de 60.729 habitantes e agrupa, no total, 27 vilas (FASC/POA, 2013). O bairro Lomba do Pinheiro, localizado na Zona Leste da cidade, fora o bairro que se apresentou como o segundo mais violento para adolescentes e jovens no período delimitado (103 mortes). A Lomba do Pinheiro constituiu-se por muito tempo como um bairro majoritariamente de características rurais, possui cerca de 62.315 habitantes e abriga, em média, 22 vilas, além das inúmeras ocupações consideradas como irregulares contidas no território, o bairro possui uma grande extensão territorial, além de contar com comunidades tradicionais indígenas, as aldeias Kaingang, Guaranis, Charruas e o núcleo familiar de Kaingangs (FASC/POA, 2013).

O terceiro bairro apresentado como o mais violento para adolescentes e jovens no período de 2015 a 2019 fora o bairro Sarandi (96 mortes). O bairro está localizado na Zona Norte de Porto Alegre e possui 91.366 habitantes (Procempa, 2013), se destacando como um bairro constituído, na década de 1940, por meio do processo de industrialização da cidade.

As análises dos indicadores sociais dos três bairros apontam para altas taxas de analfabetismo, pobreza, condições precárias de moradias, falta de acesso a políticas públicas, dentre outras estatísticas que revelam um processo constante de violações de direitos. Evidentemente, todos esses índices são atravessados pela dinâmica do racismo estrutural, uma vez que os dados evidenciam um maior impacto da violação de direitos para a população negra, sendo que recai sob essa população o caráter punitivista de Estado Penal que marca presença em uma conjuntura de avanços neoliberais.

Nesse sentido, os dados preliminares da investigação apontam uma correlação nítida entre o processo de gentirifcação, favelização e juvenicídio, sendo elementos relacionados entre em si, que: de um lado criam espaços voltados para a acumulação do capital, e de outro, territórios com populações violentadas em seus direitos básicos, onde a marcas do juvenicídio são evidentes, carregadas de dor e (in)visibilizadas pelos 
múltiplos poderes hegemônicos. Evidenciar essa realidade, possibilitando a análise das raízes que compõe tais processos são elementos necessários diante do avanço neoconservador que justifica violações de direitos e esfumaça o real em seu movimento histórico. Desmistificar as relações sociais de exploração que estão na base dos processos de juvenicídio, favelização e gentrificação mostra-se um apelo fundamental em tempos onde a racionalidade neoliberal toma diversos espaços da vida social.

\section{Considerações Finais}

O desenvolvimento do sistema capitalista, e sua lógica de produção e reprodução, determinada pelas dinâmicas das relações sociais de exploração, denotam as marcas da desigualdade social em seu desenvolvimento espacial das cidades, revelando diversas contradições e impactos para toda a população. A análise do conceito de gentrificação evidencia o processo ocorrido a partir das transformações sucedidas em diversos centros urbanos das grandes metrópoles mundiais, que tem como características o desinvestimento do poder público em infraestrutura, somado às investidas do mercado imobiliário, empresas de construção civil, corporações, comércio, mercado financeiro, etc, visando maior lucro em algumas zonas das cidades, em uma perspectiva espacial neoliberal. A partir disso, acaba atraindo a chegada de pessoas com maior poder aquisitivo, de forma que as massas populacionais residentes nesses locais são jogadas para espaços à margem dos centros das cidades, locais considerados "periféricos", se configurando como um processo de higienização social nas áreas urbanas.

Com isso, as populações que mais vivenciam o impacto da crise estrutural do capital têm maiores dificuldades, muitas vezes impossibilidades, de acessar os mais diversos serviços básicos de infraestrutura, saúde, lazer, cultura e localizados distantes de onde se concentra a maior parte dos empregos disponíveis, reflexo da segregação, muitas vezes, imposta pelo poder público e pela elite econômica, que acaba impactando diretamente na vida desses cidadãos, visto que, o território é também um espaço social vivido e dinâmico. Nesse sentido, o processo de gentrificação não pode ser descolado da produção de favelização, enquanto unidades dialéticas contraditórias constituídas na dinâmica do capital em seu atual estágio.

$\mathrm{Na}$ realidade brasileira, gaúcha e porto alegrense, este processo adquire contornos nitidamente étnico-raciais e de segregação social, com projetos institucionais 
de remoção de populações para áreas distantes, como apresentado no caso do bairro Restinga. Utiliza-se como forma de legitimação desses processos os discursos de progresso e a promessa de promover desenvolvimento modernização dos espaços geográficos. A urbanização e a formação sócio histórica de Porto Alegre passou por um processo marcado pela segregação, branqueamento de territórios com grande desigualdade social nos espaços da cidade. De maneira que a produção territorial acaba por revelar mais uma das dimensões da luta de classes. Com a produção de "bairros nobres" e a ampliação de espaços de "favelização" em determinados territórios, se configura como uma explícita contradição estrutural da cidade sob a égide neoliberal, decurso dos mais de 300 anos de escravidão no Brasil, do qual ainda vivenciamos seus efeitos nos dias atuais, que carrega consigo o pressuposto da violência e da negação de direitos. A expressão mais trágica deste processo é expresso pelos índices de mortalidade juvenil, sendo que o juvenicídio, compreendido como o homicídio de jovens canalizada pela dinâmica estrutural do capital que, sob múltiplas formas, impossibilitam a construção de projetos de vida e futuro desses sujeitos. Por fím, evidencia-se nesse contexto, a constante violência estrutural com o "pano de fundo" das demais formas de violência, naturalização da pobreza e das desigualdades sociais, que tem como componente essencial o processo de criminalização da pobreza e o racismo estrutural, acentuado em decorrência da dinâmica das relações da produção e reprodução da vida na sociedade capitalista. Diante deste contexto torna-se fundamental apontar para a importância de construção de políticas públicas intersetoriais que possa materializar a proteção social no enfrentamento a expressão mais trágica de violação de direitos: a violação do direito à vida.

\section{Referências}

ALCÂNTARA, Maurício Fernandes de. 2018. "Gentrificação". In: Enciclopédia de Antropologia. São Paulo: Universidade de São Paulo, Departamento de Antropologia. Disponível em: http://ea.fflch.usp.br/conceito/gentrificação> Acesso em 07 de julho de 2020.

ALVES, Giovanni. A condição de proletariedade. Bauru: Praxis, 2009

BARROCO, Maria Lucia S. Barbárie e neoconservadorismo: os desafios do projeto ético-político. Serv. Soc. Soc., São Paulo, n. 106, p. 205-218, abr./jun. 2011 
BARROS, B. W.; COSTA, A. P. M.; ARAUJO, G. S.; CUNHA, V. H. Territórios de morte: visibilidade dos jovens residentes em porto alegre vítimas de homicídio nos anos de 2015, 2016 E 2017. Revista de Direito da Cidade, vol. 11, nº 4, pp.225-252.

BITTENCOURT JUNIOR, I. C. Territorialidade Negra Urbana: evocação da presença. da resistência cultural, política e da memória dos negros, em Porto Alegre, delimitando espaços sociais contemporâneos. In: POSSAMAI, Zita Rosane. (Org.). Leituras da Cidade. Porto Alegre: Editora Evangraf e Ufrgs, v. 01, p. 01-314. 2010

BRASIL, Vinícius de Morais. A Copa do (a) Capital. 2015. 141f. Dissertação (Mestrado em em Ciências Sociais) - Programa de Pós-Graduação em Educação Física, Universidade Federal de Santa Maria, Santa Maria, 2015.

BRASIL. Apresentação do SIM. Secretaria de Vigilância em Saúde: Departamento de Análise de Saúde e Vigilância de Doenças Não Transmissíveis, 2017. Disponível em: http://svs.aids.gov.br/dantps/cgiae/sim/apresentacao/

CARLOS, Ana Fani Alessandri. Henri Lefebvre: o espaço, a cidade e o "direto à cidade". Rev. Direito Práx. vol.11 no.1 Rio de Janeiro Jan./Mar. 2020 Epub Mar 20, 2020

CERQUEIRA, Daniel; COELHO, Danilo Santa Cruz. Democracia racial e homicídios de jovens negros na cidade partida. Rio de Janeiro: IPEA, 2017.

DAVIS, Mike. Planeta Favela. São Paulo: Boitempo, 2006.

FARINON, Suelen Josiane. O processo de urbanização de porto alegre e suas consequências sobre a formação das sub-habitações da cidade. Monografia, Rio de Janeiro: UFRJ, 2015.

FASC. Leitura dos territórios da assistência social. Porto Alegre, 2013

FURTADO, C. R. Intervenção do Estado e (re)estruturação urbana. Um estudo sobre gentrificação. Cad. Metrop., São Paulo, v. 16, n. 32, pp. 341-363. 2014. Disponível em: http://dx.doi.org/10.1590/2236-9996.2014-3203 Acesso em: 27 de julho de 2020

da UFRGS, Porto Alegre. 2011.

Gentrificação e (re)organização urbana em Porto Alegre. Editora

GAMAlHO, N. P. Remover Para Promover: Espaço Concebido e Representações do Espaço no Bairro Restinga - Porto Alegre/RS. GEOgraphia, v. 12, n. 23. Revista do Programa de Pós-Graduação em Geografia da UFF. Rio de Janeiro. 2010. Disponível em: https://periodicos.uff.br/geographia/article/view/13591/8791 Acesso em: 27 de julho de 2020.

HARVEY, D. A produção capitalista do Espaço. São Paulo: Annablume, 2005

IBGE - Instituto Brasileiro de Geografia e Estatística. Censo demográfico, 2010. 
IBGE - Instituto Brasileiro de Geografia e Estatística. Pesquisa Nacional de Amostra por Domicílio (PNAD), 2019.

IPEA - INSTITUTO DE PESQUISA ECONÔMICA APLICADA (Org.). Atlas da violência 2017. Rio de Janeiro: Ipea; 2018.

IPEA - INSTITUTO DE PESQUISA ECONÔMICA APLICADA (Org.). Atlas da violência 2019. Rio de Janeiro: Ipea; 2019.

IPEA - INSTITUTO DE PESQUISA ECONÔMICA APLICADA (Org.). Atlas da violência 2020. Rio de Janeiro: Ipea; 2020.

JESUS, Tânia de; MOTA, Eduardo. Fatores associados à subnotificação de causas violentas de óbito. Cad. Saúde Colet., 2010, Rio de Janeiro, 18 (3): 361-70

KUHN, Fábio. Breve história do Rio Grande do Sul. Porto Alegre, Leitura XXI, 2002.

LEAL, M. C. O Estatuto da Criança e do Adolescente e a Lei de Diretrizes e Bases da Educação como marcos inovadores de políticas sociais. In: SALES, M. A.; MATOS, M. C.; _ Política social, família e juventude: uma questão de direitos. São Paulo: Cortez, 2010, p. 147 - 164

LEFEBVRE, Henri. Éléments de rythmanalyse. Paris: Syllepse, 1992.

MARX, K. O 18 de Brumário de Luís Bonaparte. São Paulo: Boitempo. 2011.

POLIDORO, Maurício; DEMICHEI, Neudy Alexandro. Porto Alegre: um século de urbanização. v. 16 n. 1 (2015): Anais do XVI ENANPUR

PROCEMPA. Bairro Sarandi. OBSERVA POA, 2015. Disponível em: http://www.observapoa.com.br/default.php?reg=422\&p_secao=17

ROLNIK, Suely. Cartografia sentimental: transformações contemporâneas do desejo. São Paulo: Estação Liberdade, 1989.

SALES, M. A.; MATOS, M. C.; Política social, família e juventude: uma questão de direitos. São Paulo: Cortez, 2010.

SALES, Apolinário Mione. (In)visibilidade perversa: adolescentes infratores como metáfora da violência. São Paulo: Cortez, 2007.

SANTOS, M. Metrópole Corporativa Fragmentada, o caso de São Paulo. São Paulo: Nobel, 1990. em: http://revistas2.uepg.br/index.php/emancipacao/article/view/10904/209209210378 Acesso em: 29 de junho de 2020.

SANTOS, Milton. Por uma outra globalização - do pensamento único à consciência universal. Rio de Janeiro: Record, 2006.

SCHERER, Giovane. Antonio. Territórios violentados e vidas descartáveis: a dinâmica espacial do capital diante da crise estrutural. EMANCIPAÇÃO (ONLINE) (PONTA GROSSA). v. 18, p. 251-265, 2018. 
SILVA, José Fernando Siqueira. O método em Marx e o Estudo da Violência Estrutural. UNESP de Franca, 2009.

SOUZA, Nali de Jesus de. Breve História da Cidade de Porto Alegre. Disponível em <https://web.archive.org/web/20140501091640/http://www.nalijsouza.web.br.com/Fun d_POA.pdf> Acesso em julho de 2020.

SMS. Sistema de Informações Municipais. Porto Alegre, 2015 a 2019. http://www2.portoalegre.rs.gov.br/sms/default.php?p_secao=919

PROCEMPA. Observa POA. http://www.observapoa.com.br/

VALENZUELA, José Manuel. Juvenicidio: Ayotzinapa y las vidas precárias en América Latina y Esapaña. $1^{\mathrm{a}}$ ed., Barcelona, 2015

Data de submissão: 15 de julho de 2020

Data de publicação: 20 de dezembro de 2021 